\title{
"PAPA PUSING" SEBAGAI UPAYA MENINGKATKAN HASIL UJIAN NASIONAL DI SD NEGERI KARANGANYAR 1
}

\section{Chusniyati Nurfadhilah}

SDN Karanganyar 1

Email: chusniyatinf@gmail.com

\section{Info Artikel}

Sejarah Artikel:

Diserahkan 10 Juni 2020

Direvisi 03 Agustus 2020

Disetujui 20 Oktober 2020

\section{Keywords:}

papa pusing

national exam score

elementary schools

\begin{abstract}
The purpose of this paper is to describe the implementation of "Papa Pusing", the results and impact, constraints, and supporting "Papa Pusing" in SD Negeri Karanganyar 1. The method in this research is descriptive method. The population in this study were students of SD Negeri Karanganyar 1. The sample in this study were students of class VI SD Negeri Karanganyar 1 in the 2015/2016 academic year. The data analysis used was descriptive quantitative.

The result of the implementation "Papa Pusing" is very effective in improving the creativity, knowledge, interest, and competence of students where from the initial conditions the average national exam of 65.2 to 72, the highest score of 26.4 UN initially increased to 28.75 and initially there are no students who scored 100 in the UN increased to two children who obtained a 100 in the UN. The effects are a lot of students who are enrolled in school favorite in the district of Kudus, students became increasingly religious, honest, disciplined and responsible, the confidence level of parents and the community increased due to the accountability of public schools also increased, the image of the school in the community the better and become an example and references other schools in the cluster-level national exam preparation. Obstacles encountered include too much pressure from parents to their children on reaching the maximum value, the absence of $U N$ facilitation for students with special needs and excessive anxiety. Factors supporting namely the support and concern of all the school community and stakeholders to realize high quality graduates and good communication between teachers and parents
\end{abstract}

\begin{abstract}
Abstrak
Penelitian ini bertujuan untuk mendeskripsikan implementasi "papa pusing", hasil dan dampak, kendala, dan pendukung "papa pusing” di SD Negeri Karanganyar 1.

Metode dalam penelitian ini adalah metode deskriptif . Populasi dalam penelitian ini adalah siswa SD Negeri Karanganyar 1. Sampel dalam penelitian ini adalah siswa kelas VI SD Negeri Karanganyar 1 Tahun Pelajaran 2015/2016. Analisis data yang digunakan secara deskriptif kuantitatif.

Hasil yang didapat adalah implementasi strategi "papa pusing" sangat efektif dalam meningkatkan kreativitas, pengetahuan, minat, dan kompetensi peserta didik dimana dari kondisi awal rata-rata ujian nasional 65,2 menjadi 72 , nilai tertinggi UN yang awalnya 26,4 meningkat menjadi 28,75. Dampak yang timbul adalah banyak siswa yang diterima di sekolah favorit di kabupaten Kudus, siswa menjadi semakin religious, jujur, disiplin dan bertanggung jawab, tingkat kepercayaan orang tua dan masyarakat meningkat karena akuntabilitas publik sekolah juga meningkat, citra sekolah di masyarakat semakin baik sehingga menjadi contoh dan rujukan sekolah lain di tingkat gugus dalam persiapan ujian nasional. Kendala yang dihadapi antara lain adanya tekanan dari orang tua yang terlalu besar agar anaknya memcapai nilai maksimal, fasilitasi UN untuk siswa berkebutuhan khusus belum ada. Faktor pendukung yaitu adanya dukungan dan kepedulian dari semua warga sekolah dan pemangku kepentingan untuk mewujudkan lulusan yang berkualitas dan adanya komunikasi antara guru dan orang tua yang terjalin baik.
\end{abstract}




\section{Chusniyati Nurfadhilah \\ "PAPA PUSING" SEBAGAI UPAYA MENINGKATKAN HASIL UJIAN NASIONAL DI SD .... WASIS: Jurnal Ilmiah Pendidikan. Volume 1 Nomor 2, November 2020, hlm. 53-59}

\section{PENDAHULUAN}

Sebagai salah satu lembaga pendidikan penyedia jasa pendidikan di Kecamatan Karanganyar yang merupakan wilayah perbatasan dengan Kabupaten Kudus, SD Negeri Karanganyar 1 harus bisa meningkatkan kapabilitas dinamis sekolah yaitu dengan memberikan layanan pendidikan yang terbaik sesuai harapan dari para orang tua siswa terhadap setiap perubahan yang terjadi. Masyarakat beranggapan bahwa sekolah yang bagus dan bermutu adalah sekolah yang punya banyak prestasi, nilai UN nya tinggi dan lulusannya bisa melanjutkan ke sekolah lanjutan yang favorit.

Pernyataan tersebut sesuai dengan Undang-Undang Republik Indonesia nomor 20 tahun 2003 bahwa dalam rangka pengendalian mutu secara nasional dilakukan evaluasi sebagai bentuk akuntabilitas penyelenggara pendidikan kepada pihak-pihak yang berkepentingan. Tentu hal ini menjadi tantangan bagi SD Negeri Karanganyar 1 untuk terus berupaya mengembangkan dan menambah diferensiasi pembelajaran dibandingkan dengan satuan pendidikan lain pada jenjang yang sama yang menjadi kompetitor dalam memberikan jasa layanan pendidikan.

Fakta di lapangan menunjukkan bahwa nilai rata-rata Ujian Nasional siswa kelas VI SD Negeri Karanganyar 1 Tahun Pelajaran 2015/2016 tergolong rendah. Siswa yang memperoleh nilai bagus didominasi oleh siswa yang pintar saja sehingga hanya beberapa siswa saja yang bisa melanjutkan ke sekolah favorit di kabupaten Kudus. Nilai rata-rata untuk mata pelajaran Ujian Nasional sangat rendah, yaitu 69,9 untuk Bahasa Indonesia, 70,0 untuk Matematika dan 55,4 untuk IPA. Meskipun secara klasikal siswa lulus $100 \%$ namun nilai rata-rata belum bisa mencapai 75,0 seperti yang diharapkan. Fakta juga menunjukkan bahwa nilai Ujian tertinggi yang diperoleh siswa hanya sebesar 26,4 (untuk nilai dalam satuan) atau 264,0 (untuk nilai dalam puluhan). Di samping itu juga tidak ada siswa yang mendapat nilai 100 untuk mata pelajaran Ujian Nasional. Kondisi demikian belum pernah terjadi pada tahun-tahun sebelumnya.

Rendahnya hasil Ujian Nasional tersebut diindikasikan karena guru belum menggunakan strategi pembelajaran yang sesuai dengan karakteristik anak dan lingkungan sekitar. Strategi pembelajaran dapat didefinisikan sebagai suatu rencana tindakan (berupa rangkaian kegiatan) termasuk penggunaan metode yang bervariasi dan pemanfaatan sumber daya kekuatan yang ada secara maksimal dalam pembelajaran (Sanjaya, 2006). Penggunaan strategi pembelajaran yang tepat dalam proses belajar mengajar sangat vital karena dapat membangun potensi, mendidik dan menciptakan pola pikir siswa yang baik dan positif. Strategi pembelajaran yang efektif diperlukan untuk mencapai tujuan pembelajaran sesuai kompetensi dan indikator dan membangun pengetahuan dan keterampilan siswa. Sebagaimana diungkapkan oleh Ruutmaan \& Kipper (2011) yang menyatakan bahwa "Knowledge of a variety of instructional strategies and flexibility to change them within and among lessons are two of greatest assets a teacher can have. Students learn in various ways, and teachers should vary their use of instructional strategies so that they can relate to their learning styles and needs."

Permasalahan rendahnya prestasi Ujian Nasional ini bila tidak segera ditanggulangi akan berakibat pada rendahnya kompetensi lulusan di tahun-tahun berikutnya sehingga akan timbul kesan bahwa sekolah menghasilkan output atau lulusan dengan sumber daya manusia (SDM) yang rendah dan kurang mampu berkompetisi dengan lulusan dari sekolah lain sehingga berdampak menurunnya kepercayaan masyarakat terhadap SD Negeri Karanganyar 1.

Oleh karena itu diperlukan suatu inovasi strategi pembelajaran yang bisa meningkatkan kembali prestasi belajar siswa dalam Ujian Nasional. Strategi pembelajaran "Papa Pusing" (Pergi Pagi Pulang Siang) merupakan implementasi dari pembelajaran komprehensif dan integratif dalam persiapan menghadapi Ujian Nasional tingkat sekolah dasar. Hal tersebut sependapat dengan Saputro (2018) yang menyatakan bahwa salah satu program sukses Ujian Nasional adalah bimbingan belajar. Kegiatan ini wujudnya adalah jam tambahan yang dilaksanakan di luar waktu KBM. Materi bimbingan belajar disesuaikan dengan indikator materi UN.

Strategi pembelajaran "papa pusing" mengacu pada teori pendekatan komprehensif integratif, yaitu strategi pembelajaran menyeluruh dan menyatu antar aspek yang saling berkaitan satu sama lain. Strategi komprehensif merupakan perpaduan metode tradisional dan masa kini meliputi penanaman nilai karakter, keteladanan, fasilitasi nilai dan pengembangan 


\section{Chusniyati Nurfadhilah \\ "PAPA PUSING" SEBAGAI UPAYA MENINGKATKAN HASIL UJIAN NASIONAL DI SD .... WASIS: Jurnal Ilmiah Pendidikan. Volume 1 Nomor 2, November 2020, hlm. 53-59}

soft skill siswa sehingga mampu berpikir kritiis, kreatif dan menjalin komunikasi sosial dengan baik. (Zuchdi dkk., 2009). Pembelajaran integratif didesain untuk mengajarkan kombinasi topik-topik yang berbentuk isi yang luas dan mengorganisasi anatomi pengetahuan (Usman, 2006). Sejalan dengan pendapat tersebut, Majid (2014) menyatakan bahwa dalam pembelajaran integratif (integrative instruction) siswa dituntut untuk aktif menggali, menemukan dan menyampaikan konsep ilmu pengetahuan yang holistik dan bermakna. Pendapat tersebut mengandung makna bahwa dalam pembelajaran integratif merupakan pembelajaran yang memiliki visi bukan hanya menyampaikan pembelajaran tetapi lebih kepada bagaimana siswa bukan hanya mendapat ilmu pengetahuan semata tetapi bagaimana siswa mendapat ilmu pengetahuan secara menyeluruh, mendalam, dan luas

Penerapan strategi "Papa Pusing" diharapkan dapat membantu siswa menyiapkan Ujian Nasional. Pendapat tersebut sejalan dengan pernyataan Purnamasari (2013) yang mengungkapkan bahwa persiapan ujian nasional dapat ditunjang dengan latihan pembelajaran yang dilakukan secara intensif dengan tingkat frekuensi pelaksanaan yang tinggi. Kegiatan tersebut dilakukan agar siswa dapat mencapai hasil ujian nasional yang maksimal melalui pengulangan-pengulangan latihan soal yang memiliki tipe dan karakter sama.

Penelitian ini bertujuan untuk 1) mendeskripsikan implementasi "papa pusing" di SD Negeri Karanganyar 1, 2) mendeskripsikan hasil pembelajaran dan dampak implementasi "papa pusing" di SD Negeri Karanganyar 1, 3) mendeskripsikan kendala implementasi "papa pusing" di SD Negeri Karanganyar 1, 4) mendeskripsikan faktor pendukung implementasi "papa pusing" di SD Negeri Karanganyar 1, dan 5) mendeskripsikan alternatif pengembangan "papa pusing” di SD Negeri Karanganyar 1.

\section{METODE PENELITIAN}

Penelitian ini menggunakan metode deskriptif. Populasi dalam penelitian ini adalah siswa SD Negeri Karanganyar 1. Sampel dalam penelitian ini adalah siswa kelas VI SD Negeri Karanganyar 1 Tahun Pelajaran 2015/2016. Teknik pengumpulan data menggunakan tes. Instrumen pengumpulan data menggunakan tes dalam bentuk pilihan ganda yang duwujudkan melalui try out UN. Analisis data yang digunakan secara deskriptif kuantitatif dengan membandingkan nilai rata-rata sebelum dan sesudah perlakukan startegi papa pusing

Penelitian ini dilakukan selama 1 semester pada semester 2 tahun pelajaran 2015/2016 di kelas VI SD Negeri Karanganyar 1. Langkah penerapan startegi papa pusing dapat dilihat pada gambar di bawah ini.

\begin{tabular}{|ll|}
\hline \multicolumn{1}{|c|}{ Perencanaan } \\
\hline 1. & $\begin{array}{l}\text { Mengkaji langkah strategi pembelajaran komprehensif } \\
\text { dan integratif }\end{array}$ \\
2. & Konsultasi dengan Kepala Sekolah \& Komite Sekolah \\
3. & Sosialisasi Program kepada Orang Tua/Wali Siswa \\
4. & Menyusun draft kegiatan saat jam pelajaran tambahan \\
5. & Mengkaji kisi-kisi Ujian Nasional \\
\hline \multicolumn{1}{|c|}{ Pelaksanaan } \\
\hline 1. & Mengularng Materi Pelajaran \\
2. & Prediksi Soal UN \\
3. & Try Out UN \\
4. & Bimbingan dan Pemberian Trik Menjawab Soal UN \\
5. & Bimbingan dan Latihan Mengisi LJK \\
6. & Bimbingan Mental dengan penanaman sikap positif \& \\
motivasi
\end{tabular}

Gambar 1. Langkah Kegiatan Implementasi Strategi Pembelajaran Papa Pusing

\section{HASIL DAN PEMBAHASAN}

\section{Implementasi "Papa Pusing"}

Implementasi "Papa Pusing" dilakukan dalam tiga tahap yaitu perencanaan, pelaksanaan, dan evaluasi. Pada tahap perencanaan meliputi mengkaji langkah-langkah strategi pembelaajran "papa pusing" yang mengadospi konsep pembelajaran komprehensif dan integrative. Langkah ini dimaksudkan untuk memperoleh desain pelaksanaan lengkap dengan jadwal dan renana kegiatan disetiap pertemuannya. Langkah selanjutnya yaitu konsultasi dengan kepala sekolah dan komite tentang strategi "papa pusing". Konsultasi ini dimaksudkan untuk meminta pendapat dan persetujuan untuk pelaksanaan strategi tersebut. Hasil konsultasi 


\section{Chusniyati Nurfadhilah \\ "PAPA PUSING" SEBAGAI UPAYA MENINGKATKAN HASIL UJIAN NASIONAL DI SD .... WASIS: Jurnal Ilmiah Pendidikan. Volume 1 Nomor 2, November 2020, hlm. 53-59}

dengan kepala sekolah dan komite ternyata mendukung pelaksanaan startegi tersebut.

Langkah berikutnya yaitu sosialisasi program "papa pusing" berupa tambahan jam pelajaran di pagi dan siang hari kepada orang tua siswa. Tujuannya adalah agar orang tua memberi perhatian lebih kepada putra-putrinya selama mengikuti persiapan Ujian Nasional. Hasil sosialisasi menunjukkan bahwa orang tua menyambut baik langkah sekolah dalam memberikan bimbingan ekstra berupa tambahan jam pelajaran pagi dan siang. Langkah berikutnya menyiapkan perangkat pendukung dengan mengkaji kisi-kisi Ujian Nasional yang terbaru, membandingkan dengan kisi-kisi tahun sebelumnya, menyiapkan bahan ajar, soal latihan dan prediksi soal serta lembar jawab komputer dan alat tulis yang diperlukan saat Ujian Nasional.

Pada tahapan pelaksanaan diujicobakan strategi pembelajaran dengan pendekatan "papa pusing" di kelas 6. Langkah-langkah kegiatan pembelajaran yang menggunakan strategi "papa pusing" yaitu siswa diminta datang lebih awal yaitu pukul 06.00 untuk mengikuti jam pelajaran tambahan yang diisi dengan berbagai kegiatan persiapan Ujian Nasional. Selanjutnya Siswa diminta tidak pulang sekolah terlebih dahulu untuk mengikuti bimbingan persiapan Ujian Nasional. Suardana dan Simarmata (2013) mengungkapkan bahwa persiapan yang dilakukan sebelum Ujian Nasional dapat mengurangi tingkat kecemasan siswa. Kegiatan yang dilakukan pada saat tambahan pelajaran adalah mengulang materi pelajaran. Kegiatan ini bertujuan untuk menyegarkan kembali ingatan siswa terhadap konsep materi yang telah berlalu terutama materi pada saat kelas 4 dan 5. Dengan mengulang materi, siswa akan menjadi ingat dan mampu menguasai konsep kembali dengan baik. Kegiatan lain yang dilakukan adalah membuat prediksi soal-soal ujian nasional dan melakukan tryout Ujian Nasional. Kegiatan ini bertujuan untuk mengatahui sejauh mana penguasaan konsep dan materi Ujian Nasional, sehingga dengan persiapan dapat mengurangi kecemasan siswa terhadap Ujian Nasional.

Di sela-sela kegiatan pengulangan materi dan pembahasan soal latihan ujian, siswa diberikan bimbingan dan trik menjawab soal-soal Ujian Nasional dengan tujuan agar siswa dapat mengerjakan soal ujian dengan efektif dan efisien. Sejalan pendapat Rizqa (2014) kegiatan bimbingan dapat membantu siswa dalam persiapan ujian nasional. Hal ini akan berdampak pada kebiasaan positif siswa ketika mengerjakan soal ujian. Kegiatan lainnya yaitu berupa mimbingan dan latihan mengerjakan lembar jawab komputer. Melalui kegiatan ini, akhirnya siswa dapat mengisi LJK dengan baik dan tidak melakukan kesalahan yang dapat menyebabkan tidak terbacanya LJK pada sisten scanning komputer. Kegiatan bimbingan mental spiritual siswa dengan melakukan pendekatan persuasive penanaman sikap positif dan optimis dalam menghadapi Ujian Nasional. Penguatan motivasi belajar siswa dengan meyakinkan siswa bahwa mereka bisa melalui Ujian Nasional dengan sukses sesuai dengan kemampuan masingmasing siswa. Kegiatan di akhiri dengan acara istighosah dan doa bersama serta permohonanan doa restu.

Kegiatan evaluasi dilakukan oleh kepala sekolah dan guru kelas VI tidak hanya sebulan sekali tetapi dilakukan secara berkesinambungan sesuai dengan progress kemajuan siswa. Kegiatan yang dilakukan adalah evaluasi terhadap jadwal pelaksanan jam tambahan pelajaran pagi dan siang. Hal ini dilakukan untuk mengetahui apakah kegiatan penambahan jam pelajaran benar-benar dilaksanakan atau tidak. Hasilnya ternyata kegiatan tersebut dilaksanakan secara rutin dan diikuti dengan sangat baik oleh siswa. Anak menjadi semakin disiplin dan bertanggung jawab karena terbiasa berangkat lebih pagi untuk menerima pelajaran lebih awal.

Kegiatan evaluasi selanjutnya adalah evaluasi terhadap hasil latihan ujian berupa tryout baik tryout tingkat sekolah, kecamatan maupun kabupaten. Dari evaluasi ini akan diketahui sejauh mana progreas kemajuan penguasaan teori siswa terhadap setiap indicator soal dalam Ujian Nasional. Dari hasil tryout dapat digunakan untuk memberikan bimbingan yang lebih kepada siswa yang masih mengalamai kesulitan. Kegiatan evaluasi berikutnya adalah evaluasi terhadap pengisian LJK. Evaluasi ini dimaksudkan untuk mengetahui tingkat pemahaman siswa dalam mengisi lembar jawab komputer. Ketepatan dalam mengisi LJK akan mempengaruhi proses scanning oleh komputer. Dari evaluasi ini akan diketahui siswa mana saja yang masih mengalamai kesulitan dalam mengisi LJK.

Kegiatan evaluasi selanjutnya adalah evaluasi terhadap perkembangan mental dan sikap positif siswa dalam menghadapi Ujian Nasional. Menurut Rizqa (2014) bimbingan 


\section{Chusniyati Nurfadhilah \\ "PAPA PUSING" SEBAGAI UPAYA MENINGKATKAN HASIL UJIAN NASIONAL DI SD .... WASIS: Jurnal Ilmiah Pendidikan. Volume 1 Nomor 2, November 2020, hlm. 53-59}

mental dan spiritual penting dilakukan untuk memantapkan persiapan siswa. Dari evaluasi ini akan menunjukkan kesiapan mental siswa. Dari evaluasi ini juga dapat dilihat apakah siswa mengalami stress berlebih apa tidak sehingga bisa ditentukan tindakan untuk mengurangi stress. Evaluasi berikutnya adalah evaluasi terhadap peran serta orang tua dalam memberi dukungan terhadap putra putrinya. Evaluasi ini dilakukan dengan cara mengundang beberapa orang tua siswa untuk diajak berdiskusi terhadap perkembangan pembelajaran siswa selama persiapan Ujian Nasional.

\section{Peningkatan Nilai Ujian Nasional}

Secara keseluruhan strategi pembelajaran "papa pusing" berjalan sangat baik meskipun masih ada kendala yang mengganggu pelaksanaan strategi pembelajaran "papa pusing". Pada akhir Ujian Nasional siswa kelas VI SD Negeri Karanganyar 1, peneliti mencatat dan menganalisa hasil belajar pada daftar nilai untuk mengetahui tingkat keberhasilan setelah mengikuti mengikuti pembelajaran "papa pusing". Adapun peningkatan hasil nilai Ujian Nasional setelah menggunakan strategi pembelajaran "papa pusing" dapat dilihat dalam tabel berikut.

Tabel 1. Rekapitulasi Hasil Nilai Ujian Nasional

\begin{tabular}{cccc}
\hline \multirow{2}{*}{ No } & \multirow{2}{*}{ Uraian } & \multicolumn{2}{c}{ Hasil UN } \\
\cline { 3 - 4 } & & Try Out UN & UN \\
\hline 1 & Ketuntasan & $100 \%$ & $100 \%$ \\
\hline 2 & Nilai Rata-rata & $65,22(6,52)$ & $72,53(7,25)$ \\
\hline 3 & Nilai Terendah & $153,5(15,35)$ & $126,0(12,6)$ \\
\hline 4 & Nilai Tertinggi & $264,0(26,4)$ & $287,5(28,75)$ \\
\hline
\end{tabular}

Dari tabel di atas diektahui bahwa terjadi peningkatan hasil Ujian Nasional. Nilai rata-rata UN mengalami peningkatan dari 65,22 pada saat Try Out UN meningkat menjadi 72,53 pada saat Ujian Nasional di tahun pelajaran 2015/2016. Nilai tertinggi yang di raih siswa juga mengalami peningkatan, yaitu 264,0 pada saat Try Out Ujian Nasional meningkat menjadi 287,5 saat Ujian Nasional di tahun pelajaran 2015/2016. Nilai terendah mengalami penurunan pada saat Try Out 153,5 mengalami penurunan menjadi 126 saat Ujian Nasional dikarenakan pada tahun 2015/2016 terdapat siswa berkebutuhan khusus yang seharusnya tidak mengikuti UN regular namun dipaksakan mengikuti karena kebijakan dari kabupaten. Indikator keberhasilan lainnya dapat dilihat dari perolehan nilai tiap mata pelajaran UN seperti berikut ini.

Tabel 2. Rekapitulasi Hasil Nilai UN tiap Mapel

\begin{tabular}{lccccccc}
\hline \multirow{2}{*}{ No } & \multicolumn{3}{c}{ Uraian } & \multicolumn{3}{c}{ Try Out UN } & \multicolumn{3}{c}{ UN } \\
\cline { 2 - 7 } & & BI & Mtk & IPA & BI & Mtk & IPA \\
\hline 1 & Nilai Tertinggi & 84,0 & 97,5 & 82,5 & 92,4 & 100 & 100 \\
\hline 2 & Nilai Terendah & 46,0 & 45,0 & 40,0 & 46,0 & 27,5 & 42,5 \\
\hline 3 & Nilai Rata-rata & 69,9 & 70,0 & 55,7 & 73,5 & 64,4 & 79,7 \\
\hline
\end{tabular}

Dari Tabel 2 di atas diketahui bahwa nilai tertinggi untuk mata pelajaran UN meningkat saat Try Out dan Ujian Nasional, bahkan sudah ada yang mencapai nilai 100 untuk mata pelajaran matematika sebanyak 2 anak dan nilai 100 mata pelajaran IPA sebanyak 1 anak. Nilai rata-rata untuk mata pelajaran bahasa Indonesia dan IPA mengalamai peningkatan sedangkan nilai rata-rata matematika mengalami penurunan. Hal ini perlu didalami kembali untuk persiapan UN yang akan datang. Namun secara klasikal terjadi peningkatan yang cukup signifikan dibanding nilai Try Out UN sebelumnya.

Peningkatan hasil belajar juga tampak pada nilai sikap dan keterampilan. Peningkatan nilai sikap peserta didik meliputi aspek sikap spiritual dan sikap sosial. Pada sikap spiritual peserta didik mulai terbiasa mengungkapkan rasa syukur terhadap Tuhan YME. Nilai sikap ini mulai tumbuh ketika peserta didik banyak melakukan kegiatan di luar kelas berupa Sholat Dhuhur berjamaah sesaat sebelum mengikuti jam pelajaran tambahan pada siang hari dan setelah mengikuti kegiatan doa bersama dan istighosah. Sikap sosial yang mulai berkembang pada kegiatan "papa pusing" ini yaitu kerja sama, kepedulian sosial, disiplin, kejujuran, mandiri, dan tanggung jawab. Tumbuhnya sikap sosial tersebut dapat terlihat ketika peserta didik bekerja sama dalam kelompok ketika mengerjakan tugas, pada saat kegiatan mengomunikasikan, berdiskusi dan menjawab soal-soal latihan saat pembahasan soal berlansung. Siswa terbiasa jujur dalam mengerjakan soal ujian nasional karean merasa percaya diri terhadap kemampuan diri sendiri. Tumbuhnya sikap keterampilan dapat diamati ketika siswa mengerjakan tugas. Siswa ada kemajuan keterampilan menganalissi soal ujian dan menemukan jawaban yan tepat sesuai dengan trik yang diberikan oleh guru. 


\section{Chusniyati Nurfadhilah \\ "PAPA PUSING" SEBAGAI UPAYA MENINGKATKAN HASIL UJIAN NASIONAL DI SD .... WASIS: Jurnal Ilmiah Pendidikan. Volume 1 Nomor 2, November 2020, hlm. 53-59}

\section{Dampak Penerapan "Papa Pusing”}

Pelaksanaan pembelajaran "papa pusing" dalam meningkatkan hasil ujian nasional di SD Negeri Karanganyar 1 memiliki dampak sebagai berikut (1) semakin banyak siswa yang diterima di sekolah favorit di kabupaten Kudus yaitu SMP 1 Kudus, SMP 2 Kudus, Banat Kudus, SMP 1 Jati Kudus dan SMP 2 Jati Kudus yang merupakan sekolah RSBI dan SSN. (2) Siswa menjadi semakin religious, jujur, disiplin dan bertanggung jawab. (3) Di samping itu tingkat kepercayaan orang tua dan masyarakat untuk menyekolahkan anaknya di SD Negeri Karanganyar 1 juga meningkat karena akuntabilitas publik sekolah juga meningkat. Citra sekolah di masyarakat juga semakin baik. (4) SD Negeri Karanganyar 1 menjadi contoh dan rujukan sekolah lain di tingkat gugus dalam rangka meningkatkan hasil ujian nasional.

Kendala-Kendala yang Dihadapi dalam Melaksanakan Strategi yang Dipilih

Kendala yang dihadapi dalam implementasi "papa pusing" antara lain (1) Adanya tekanan yang terlalu besar dari orang tua agar anaknya memcapai nilai maksimal. Tekanan ini muncul karena orang tua terlalu bersemangat dan over confidence terhadap startegi pembelajaran "papa pusing". (2) Kendala lainnya adalah tidak adanya fasilitasi ujian nasional dari pemerintah untuk siswa berkebutuhan khusus sehingga dengan keterpaksaan siswa berkebutuhan khusus dengan segala kekurangan yang dimiliki harus mengikutu ujian nasional secara reguler seperti siswa normal lainnya. (3) Kendala selanjutnya adalah kecemasan yang berlebihan dari beberapa siswa terhadap hasil ujian nasional. Meskipun secara komprehensif siswa dibimbing baik secara kognitif, psikomotorik dan afektif, ternyata rasa cemas masih tetap timbul dalam diri beberapa siswa.

\section{Faktor-Faktor Pendukung}

Beberapa faktor pendukung sebagai penguat penerapan pembelajaran "papa pusing" antara lain (1) Adanya dukungan dan kepedulian dari semua warga sekolah dan pemangku kepentingan untuk mewujudkan lulusan yang berkualitas. Dukungan dan kepedulian ini ditunjukkan dengan memberikan apresiasi, saran dan kritik yang membangun terhadap pelaksanaan strategi pembelajaran "papa pusing”. (2) Faktor pendukung lainnya adalah orang tua siswa dan guru senantiasa berkomunikasi terkait dengan perkembangan anak-anaknya dalam persiapan ujian nasional sehingga siswa percaya diri terhadap kemampuannya. Rini (2014) menyampaikan bahwa keyakinan seseorang terhadap kemampuannya saat diperlukan dalam menghadapi ujian nasional. Adanya kedekatan hubungan antara orang tua dan guru memudahkan guru dalam menganalisa progress kemampuan siswa dalam menerima konsep materi yang dipelajari selama persiapan mengikuti ujian nasional. Bahkan cukup banyak orang tua yang mengantarkan dan menjemput anaknya selama persiapan ujian nasional demi tercapainya hasil ujian yang maksimal.

\section{Alternatif Pengembangan}

Program pengembangan sekolah ke depan harus diarahkan kepada penguatan pembelajaran "papa pusing" dengan menambah jenis dan kegiatan lainnya yang mendukung tercapaianya hasil ujian nasional yang maksimal sehingga diperoleh lulusan yang memiliki daya saing tinggi. Alternatif pengembangan yang bisa dilakukan adalah dengan menambah variabel program atau kegiatan misalnya menjadi "papa pusing dikarantina" yaitu strategi pembelajaran yang sudah ada ditingkatkan lagi dengan menambah jadwal karantina selama ujian nasional berlangsung. Dengan demikian siswa akan terpantau secara maksimal proses belajarnya selama ujian nasional berlangsung.

Disamping itu, diperlukan guru yang profesional untuk mengimpelemnetasikan dan mengembangkan strategi pembelajaran "papa pusing" dengan cara senantiasa meningkatkan kreativitasnya dalam mengembangkan kompetensinya sebagai seorang guru sesuai dengan situasi dan kondisi di lingkungan sekolah. Tentu saja harus ada pendampingan dan bimbingan dari kepala sekolah dan pengawas sekolah.

\section{SIMPULAN}

Berdasarkan hasil dan pembahasan yang telah diuriaikan, dapat disimpulkan sebagai berikut:

1. Implementasi "papa pusing" dilaksanakan dengan menerapkan pembelajaran komprehensif dan integratif dengan langkahlangkah analisis kisi-kisi, mengulang pelajaran, prediksi soal dan latihan ujian nasional, bimbingan strategi menjawab soal secara efektif dan efisien, bimbingan 


\section{Chusniyati Nurfadhilah \\ "PAPA PUSING" SEBAGAI UPAYA MENINGKATKAN HASIL UJIAN NASIONAL DI SD .... WASIS: Jurnal Ilmiah Pendidikan. Volume 1 Nomor 2, November 2020, hlm. 53-59}

pengisian LJK, bimbingan dan motivasi sikap mental dan spiritual siswa dan berdoa serta mohon doa restu kepada orang tua, guru dan kyai. Setiap kegiatan dilaksanakan secara komprehensif dan integratif dengan berprinsip pada pembelajaran Pakem

2. Hasil yang diperoleh setelah pelaksanaan pembelajaran "papa pusing" adalah terjadi peningkatan hasil UN. Rata-rata nilai UN yang awalnya 65,22 saat Try Out UN meningkat menjadi 72,53 saat UN di tahun pelajaran 2015/2016. Nilai tertinggi juga meningkat, yaitu 264,0 saat Try Out UN menjadi 287,5 saat UN di tahun pelajaran 2015/2016. Nilai tertinggi untuk mata pelajaran UN meningkat dari hasil Try Out UN, bahkan sudah ada yang mencapai nilai 100 untuk mata pelajaran matematika sebanyak 2 anak dan nilai 100 mata pelajaran IPA sebanyak 1 anak.

3. Dampak yang timbul dari implementasi "papa pusing" adalah semakin banyak siswa yang diterima di sekolah favorit di kabupaten Kudus yaitu SMP 1 Kudus, SMP 2 Kudus, Banat Kudus, SMP 1 Jati Kudus dan SMP 2 Jati Kudus yang merupakan sekolah RSBI dan SSN. Siswa menjadi semakin religious, jujur, disiplin dan bertanggung jawab. Siswa Di samping itu tingkat kepercayaan orang tua dan masyarakat untuk menyekolahkan anaknya di SD Negeri Karanganyar 1 juga meningkat karena akuntabilitas public sekolah juga meningkat. Citra sekolah di masyarakat juga semakin baik.

4. Kendala yang dihadapi dalam implementasi "papa pusing" antara lain adanya tekanan yang terlalu besar dari orang tua agar anaknya memcapai nilai maksimal, tidak adanya fasilitasi ujian nasional dari pemerintah untuk siswa berkebutuhan khusus dan kecemasan yang berlebihan dari beberapa siswa terhadap hasil ujian nasional.

5. Faktor pendukung implementasi "papa pusing" yaitu adanya dukungan dan kepedulian dari semua warga sekolah dan pemangku kepentingan untuk mewujudkan lulusan yang berkualitas, orang tua siswa dan guru senantiasa berkomunikasi terkait dengan perkembangan anak-anaknya dalam persiapan ujian nasional.

\section{DAFTAR PUSTAKA}

Majid, Abdul 2014. Pembelajaran Tematik Terpadu. Bandung : Remaja Rosda Karya.

Purnamasari, Diah Ayu. 2013. Strategi Meningkatkan Hasil Ujian Nasional Mata Pelajaran Ekonomi. Jurnal Ilmiah Pendidikan Ekonomi IKIP Veteran Semarang. 1 (2), 38-48

Rini H.P. 2013. Self Efficacy Dengan Kecemasan Dalam Menghadapi Ujian Nasional, Cognicia, 1(1).

Rizqa, Miftahir. 2014. Evaluasi Progam Strategi Menghadapi Ujian Nasional di MTsN Model Padang tahun 2008. Jurnal Penelitian Sosial Keagamaan, 17 (2)

Sanjaya, Wina. 2006. Strategi Pembelajaran. Jakarta : Kencana Prenada Media Group

Saputro, WJ. 2018. Pengelolaan Program Sukses Ujian Nasional Matematika Di Sekolah Berbasis Pondok Pesantren. Naskah Publikasi Ilmiah. Universitas Muhammadiyah Surakarta.

Suardana AAPCP., \& Simarmata N. 2013. Hubungan Antara Motivasi Belajar dan Kecemasan Pada Siswa Kelas VI Sekolah Dasar Di Denpasar Menjelang Ujian Nasional. Jurnal Psikologi Udayana, 1(1):203-212

Usman, Mohammad Uzer. 2006. Menjadi Guru Profesional. Bandung: Remaja Rosda Karya.

Undang-undang Nomor 20 Tahun 2003 tentang Sistem Pendidikan Nsional.

Zuchdi, Darmiyati. 2009. Humanisasi Pendidikan. Jakarta: Bumi Aksara 